\title{
Domestic violence: the shaken adult syndrome
}

\author{
T D Carrigan, E Walker, S Barnes
}

\begin{abstract}
A case of domestic violence is reported. The patient presented with the triad of injuries associated with the shaking of infants: retinal haemorrhages, subdural haematoma, and patterned bruising; this has been described as the shaken adult syndrome. This case report reflects the difficulties in diagnosing domestic violence in the accident and emergency setting.

(f Accid Emerg Med 2000;17:138-139)
\end{abstract}

Keywords: domestic violence; women; assault

Domestic violence is an under-reported and major public health problem that often first presents to the accident and emergency (A\&E) department. It accounts for half of all violent crimes against women, and two deaths per week have been linked to domestic violence in Britain. ${ }^{1}$ Indeed, the Department of Health has issued statements to ensure health professionals are aware of domestic violence in this context when patients present with consistent traumatic injuries. $^{2}$

The following case report reflects the difficulties in diagnosing domestic violence in the $A \& E$ setting, and stresses the timely referral of such patients to the relevant authorities.

\section{Case report}

A 34 year old woman was brought to the A\&E department by ambulance at 0400 hours with head injuries. When handed over from the ambulance crew an assault was queried, although the patient later stated she had fallen down stairs after moderate alcohol ingestion.
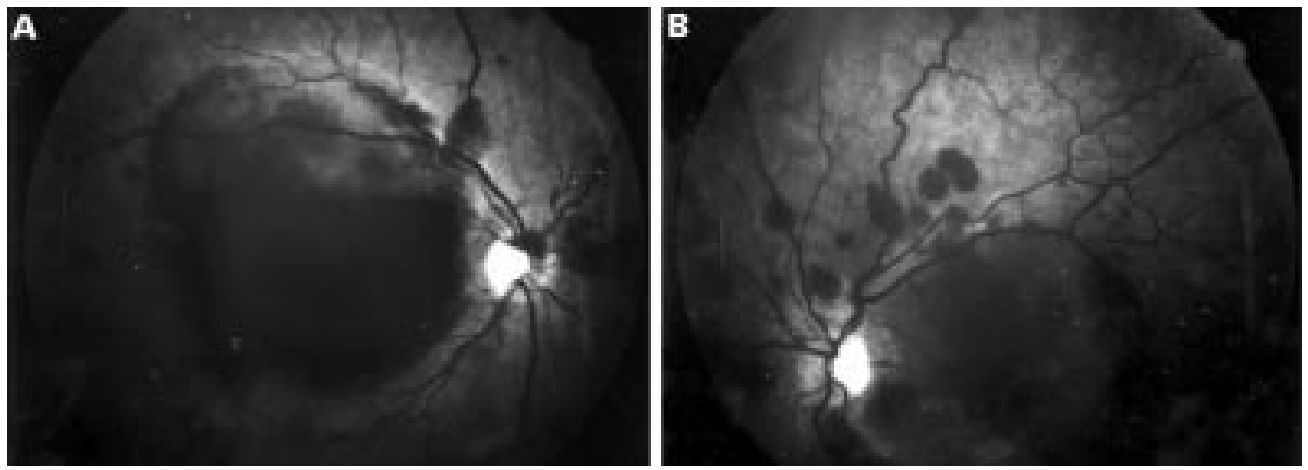

Figure 1 Photographs showing (A) retinal haemorrhage in the right eye and $(B)$ retinal and preretinal haemorrhages in the left eye.

Her initial blood pressure was 119/72 mm $\mathrm{Hg}$, pulse 88 beats/min, her pupils were equal and reactive directly and consensually, and her Glasgow coma score was 13/15 (she was confused and was opening her eyes to command). Examination of the head showed bilateral periorbital ecchymoses, nasal bridge swelling and epistaxis, a right frontal abrasion, and an occipital scalp haematoma. Ecchymoses were also noted on her back and buttocks, being linear in fashion on both upper arms, and her underpants were torn. Initial skull and facial $x$ ray films were normal, and she was admitted under the care of $A \& E$ for neurological observations.

Over the next 24 hours, her Glasgow coma score improved to $15 / 15$, but she had vomited five times and complained that her vision remained blurred. Visual acuity was only hand movements in the right eye and finger counting in the left. Ophthalmological review confirmed both retinal and preretinal haemorrhages in the right eye and a retinal haemorrhage on the left. Both maculae were affected by the haemorrhage (fig 1). Haematological investigations, including a full blood count and a clotting screen, were within normal parameters, and computed tomography of the head revealed a small left temporal subdural haemorrhage with adjacent oedema.

It was only after 48 hours and repeated advice that she should seek help and report the injuries to the police, that she admitted that domestic violence had occurred.

Ongoing police and consultant medical review showed photographic evidence of patterned bruising to the upper arms, and also several circular burns to the face and arm, similar to the type caused by the deliberate

Accident and Emergency

Department,

Dewsbury District

Hospital, Dewsbury

T D Carrigan

E Walker

$S$ Barnes

Correspondence to: Dr T D Carrigan, Specialist Registrar, Accident and Emergency Department, St James's University Hospital, Beckett Street, Leeds LS9 $7 \mathrm{TF}$

Accepted 28 September 1999 
application of lit cigarettes. She suffered postconcussional symptoms for two weeks. Five weeks after the initial injury she reattended with persistent atypical chest pain. Three months later her visual acuity had improved on the left to $6 / 24$, but remained unchanged on the right, and a vitrectomy was contemplated for that side.

\section{Discussion}

This patient had the diagnostic triad of retinal haemorrhages, subdural haematoma, and patterned bruising that is associated with forceful and repeated shaking of infants. Such a triad has previously been documented postmortem in a Palestinian adult who died under interrogation by the Israeli security forces, and has been described as the shaken adult syndrome. ${ }^{3}$

Even when the presenting history is misguiding, all injuries must be thoroughly documented, and appropriate treatment instituted. Management also involves guiding the patient to autonomously decide whether to accept help and/or legal assistance. In most states of America, it is mandatory to report domestic violence related injuries, though the American College of Emergency Physicians oppose this, stating that reporting should be in accordance with the patient's wishes. ${ }^{4}$ Confidentiality was considered in this case, and gradual discussion broke down the barriers of denial. Eventual admission of domestic violence took three days though, a luxury not often available to emergency clinicians.

Early detection and documentation of injuries consistent with domestic violence must be attempted, and in this case, earlier documentation of visual acuity would have facilitated an earlier diagnosis of retinal haemorrhage.
The diagnosis of "shaken adult syndrome" was eventually made, supported by delayed diagnosis of some of the classical signs consistent with non-accidental injury.

Domestic violence victims are often discharged home the same day, thus losing that window of opportunity to allow for intrinsically motivated acceptance of help. Not all A\&E departments have access to their own observation beds, though many departments are now managing head injuries, especially now that neurosurgical care has centralised to regional centres of excellence.

The way forward should be a more structured method of follow up of suspected victims of domestic violence that is initiated in the A\&E department. As it is in suspected paediatric non-accidental injury, so one can prevent repeat episodes to not only the patient, but also to their children and other family members. The A\&E department should grasp this initiative.

Contributors

Thomas Carrigan, guarantor of the case report, initiated and coordinated the collection of the clinical history, investigation confirmation, and writing of the abstract.

Ed Walker was involved with interpretation of the case, background research, and writing of the report. Dr Barnes was involved with the critical revision of the report, and with the collation of photographic evidence of the patient.

Conflict of interest: none.

Funding: none.

1 Hall C. One in four women face violence in the home. Daily Telegraph, 1 July 1998

2 Department of Health NHS Executive. Domestic violence. London. Department of Health, 1997.

3 Pounder D. Shaken adult syndrome. Am 7 Forensic Med Pathol 1997:18:321-4.

4 American College of Emergency Physicians. Mandatory reporting of domestic violence to law enforcement and criminal justice agencies. Ann Emerg Med 1997;30:561.

\title{
Airbag associated fatal head injury: case report and review of the literature on airbag injuries
}

\author{
K Cunningham, T D Brown, E Gradwell, P A Nee
}

Whiston Hospital, Prescot, Merseyside L35 5DR: Department of Accident and Emergency Medicine K Cunningham T D Brown

P A Nee

Department of Pathology E Gradwell

Correspondence to: Dr Cunningham (e-mail: kieran-c@email.msn.com)

Accepted 10 November 1999

\begin{abstract}
Airbags have been shown to significantly reduce mortality and morbidity in motor vehicle crashes. However, the airbag, like the seat belt, produces its own range of injuries. With the increasing use of airbags in the UK, airbag associated injuries will be seen more often. These are usually minor, but in certain circumstances severe and fatal injuries result. Such injuries have been described before in the medical literature, but hitherto most reports have been from North America. This is the first case report from the UK of serious injury due to airbag deployment and describes the case of a driver who was fatally injured when her airbag deployed
\end{abstract}

in a moderate impact frontal collision where such severe injury would not normally have been anticipated. The range of airbag associated injuries is described and predisposing factors such as lack of seat belt usage, short stature, and proximity to airbag housing are discussed. The particular dangers airbags pose to children are also discussed.

(f Accid Emerg Med 2000;17:139-142)

Keywords: airbags; head injury

The introduction of airbags has led to a significant reduction in morbidity and mortality from road traffic accidents. ${ }^{12}$ However, the airbag like the seat belt produces its own range of 
injuries. In the case of the airbag this ranges from relatively minor injuries, such as abrasions and superficial burns to unexpected fatalities. Case reports of such fatalities have appeared in the North American literature since $1993,{ }^{34}$ but hitherto none have been reported from the UK.

\section{Case report}

A 47 year old woman driving a 1997 registered Rover 414 at an estimated $19 \mathrm{mph}$ was involved in a head-on collision with a 13 year old Opel Ascona driven at approximately $27 \mathrm{mph}$. There was structural damage to the front end and bonnet of the Rover but no substantial intrusion into the passenger compartment and the windscreen remained intact. The driver of the Rover had been wearing her seat belt and her airbag was deployed. She appeared to be unconscious in the vehicle and the emergency services were activated by a passer-by. The driver of the Opel was a 21 year old male. His vehicle was not equipped with an airbag, but he had been wearing his seat belt. He was uninjured apart from a cut lip and was ambulant at scene. A paramedic crew arrived approximately 10 minutes after the crash. The patient was unresponsive during extrication and a Glasgow coma score of 3 was recorded at scene (no eye opening, no motor response to painful stimuli, and no vocalisation). She was noted to have Cheyne-Stokes respirations and a palpable radial pulse. She was intubated and intravenous access was established. During transport to hospital the patient became asystolic and advanced cardiac life support was initiated according to standard protocols. $^{5}$

On arrival in the emergency department there were no signs of life and asystole was apparent on the monitor. Bruising to the abdomen and sternal area, and bleeding from both ears was noted. Resuscitation was continued according to protocol for a further five minutes without success and the patient was declared dead.

A postmortem examination was carried out the next day. There was horizontal bruising of the lower abdomen, abrasions of the left anterior iliac region, and bruising from the central sternum to the left iliac region, all consistent with a seat belt mark. In addition there was an $8 \mathrm{~cm}$ diameter bruise in the middle of the sternal region. There was blood in both external ear canals and bruising of the nasal bridge. No other major facial injuries were noted. On internal examination there was a fracture of the sternum at the junction of manubrium and body, and fractures of the fourth to seventh left ribs laterally. In the skull there was a large ring fracture beginning just behind the pituitary fossa and extending through the right temporal bone posteriorly to the midline $8 \mathrm{~cm}$ behind the foramen magnum and anteriorly through the roof of the left temporal bone to the origin. The anterior and middle cranial fossae on both sides were freely mobile around this fracture. The brain showed diffuse swelling with blood in the subarachnoid space and at the base of the brain. The spinal column and nerve cord were normal. The immediate cause of death was deemed to have been a severe head injury.

The subject of this report was a middle aged woman of stout build, height 5' 7", weight $92 \mathrm{~kg}$. Crash investigators have postulated that the unexpectedly severe injuries sustained were caused by her sitting too far forward when the airbag was deployed. As a result, the bag expanded suddenly into her chest and up towards the face, rather than the body impacting with the fully expanded bag as intended by design. This lead to sudden forced hyperextension of the head and neck resulting in the base of skull ring fracture as described.

\section{Discussion}

HISTORY AND DEVELOPMENT OF AIRBAGS

An airbag is a deflated balloon contained in the steering wheel or dashboard, which inflates rapidly on crash impact to cushion the occupant from injury within the car. Inflation is triggered by a deceleration sensor, which can be situated in various sites such as the front bumper or engine firewall. Triggering of the sensor activates a pyrotechnic device containing sodium azide that ignites producing a large volume of nitrogen gas, which then inflates the airbag to a volume of about 30 litres (Eurobag design) or about 70 litres (US full size) within $50 \mathrm{msec}$. The airbag then deflates almost immediately through vents in its lining. The timing of airbag inflation is crucial. If it fires too soon, it will already be deflating when the driver hits it, and will fail to provide any protection. If it fires too late, the driver's head will have already hit the steering wheel or will impact with the ballooning bag.

The first automobile airbag patent was filed in 1949 and issued in 1953. Since then airbag design and operation has been continually modified and improved. Design alterations have focused on such aspects as constituent materials, optimum bag size, inflation speed, and deployment threshold. However, it is only in the last decade that airbags have entered the UK car fleet in any significant numbers, and the proportion of vehicles equipped with airbags still lags well behind that in North America. Figures from the US show that in 1995 over $70 \%$ of US made new cars had airbags installed compared with $7 \%$ in 1989. Since 1998 car manufacturers in the US have been obliged to fit dual airbags in all new cars. The National Highway Traffic Safety Administration (NHTSA), a division of the US Department of Transportation, estimates that between 1986 and October 1999 airbags have saved 4758 lives (4011 drivers and 747 front passengers). This effect has occurred mainly in the last few years. ${ }^{1}$

\section{AIRBAG ASSOCIATED INJURY}

With the increasing prevalence of airbags in North America, reports began to appear in the medical literature there in the early 1990s of injuries related to airbag deployment. ${ }^{6}$ The 
different constituents of the airbag, propellant capsule $^{7}$ and chemicals, ${ }^{89}$ airbag module cover, ${ }^{10}$ and the actual bag itself, have all been implicated in different injuries. However, most of the more serious injuries are caused by the act of deployment and are secondary to the shearing forces produced by the "punch-out" of the bag. ${ }^{11-13}$

The most commonly observed injuries are minor bruises and abrasions, mainly to the face, neck, and upper limbs. ${ }^{14}$ These are often referred to as "bag slap" injuries. Some of the first reports were of eye injuries. ${ }^{6}$ The eye may be injured by the fully deployed airbag causing corneal abrasions, but more serious injuries such as retinal detachment and orbital blow out fractures can be sustained from an actively deploying airbag. ${ }^{15-17}$ These injuries may be worse if the patient is wearing spectacles. ${ }^{18}$ Also, an alkaline chemical keratitis has been reported from the combustion byproducts of the conversion of sodium azide to nitrogen. ${ }^{8}$ Superficial burns of the upper extremities, face, and neck are well documented, ${ }^{19} 20$ and full thickness burns can also occur. ${ }^{21}$ Temporary hearing impairment and tinnitus have been reported on a number of occasions. ${ }^{22} 23$ Upper limb injuries occur due to the proximity of the forearm to the deploying airbag and are caused either by direct contact with the activated bag, or by flinging the limb into interior car structures. ${ }^{24-26}$ Fractures of the forearm are rare and are usually due to direct impact with the opening of the airbag module cover. ${ }^{10}$

Minor chest injuries and rib fractures have been reported, and more serious thoracic injuries have occurred in comparatively low velocity crashes. These include rupture of the right atrium $^{27}$ and aortic dissection. ${ }^{28}$ The aerosols generated by airbag deployment have also induced exacerbations of asthma in susceptible individuals. ${ }^{9}$

\section{UNEXPECTED DEATHS}

In recent years there have been a number of reports of serious and fatal injuries occurring in low velocity crashes where the forces involved would not normally be expected to cause serious harm. ${ }^{412}{ }^{13}$ Also, the particular dangers passenger airbags pose to children placed in the front seat have been well documented. ${ }^{29}{ }^{30}$ The NHTSA Special Crash Investigation Program has identified 146 airbag related deaths to 1 October 1999, including 84 children, 18 of whom were infants in rear-facing infant seats. ${ }^{1}$ When infants are restrained in rear-facing child seats in the front passenger seat, the head and neck are close to the airbag housing and traumatic brain injuries occur after a direct blow from the rapidly inflating airbag. Children who are unrestrained or poorly restrained will often sit or stand too close to the airbag when it deploys. Similarly, such children can be thrown forwards toward the airbag in pre-impact braking, and will be in front of the deploying airbag at impact.

\section{Key messages}

- Airbags significantly reduce morbidity and mortality for adult drivers and front seat passengers in motor vehicle crashes.

- Airbags can cause serious injury or death if the occupant is too close to the airbag when it deploys.

- The risk of airbag associated injury can be minimised if all drivers wore seat belts and sat at least 10 inches from the airbag housing.

- Children should never travel in the front seat of an airbag equipped vehicle.

- More airbag associated injuries will be seen in the future and greater public awareness on airbag benefits and hazards is required.

Serious and fatal injury attributed to airbags has previously been reported mainly from North American centres. Thus far, few airbag related injuries have been reported from the UK and all have been relatively minor. Apart from the lower prevalence of airbags (which will change), there are a number of other reasons for this. Firstly, in the UK seat belt usage is mandatory and uptake is therefore much greater than in some US states. As a result, fewer British vehicle occupants rely solely on the protection afforded by the airbag. Secondly, airbags here are somewhat different. European airbags are designed primarily to protect belted drivers from making head and face contact with the steering wheel. Consequently, our airbags are smaller (average volume 30-40 litres) and deploy with much less force than the average US airbag (about 70 litres). The US airbag is designed to protect unbelted occupants, and inflation to 70 litres occurs within the same time frame (about 50 msec) - a much more violent deployment. A final point is that traffic laws have been in place here for some time which prohibit children from travelling unrestrained in the front seat.

When an adult driver or passenger is in an atypical position there is a change in the pattern of deployment of the airbag. ${ }^{31}$ Rather than preventing injury, the airbag can cause injury. This occurs primarily when the occupant is in the "deployment zone" of the airbag. Specifically, if the occupant is too near the steering wheel, the lower part of expansion of the airbag is restricted by the chest leading not only to excessive forces being applied to the thorax but also to a greater upward expansion of the bag. This can cause severe head and facial injuries with hyperextension of the neck and cervical spine injury. Reasons for being within the deployment zone include not wearing a seat belt (the commonest cause), sitting too close to the airbag housing (children and adults of short stature), and where deployment has occurred after pre-crash braking (the occupant having already been thrown forward before the airbag was deployed). The occupant could also be within the deployment 
zone if for some reason the airbag should fire late in the crash sequence. Basilar skull fractures as seen in our patient may not be uncommon in this context as illustrated by a recent report from Denmark of two similar cases. ${ }^{32}$ However, in both of these cases the drivers were unbelted. Our patient was wearing a seat belt, and the exact contribution of individual factors (such as initial seating position and pre-crash braking) that were responsible for placing her too close to the expanding airbag are not certain. All of these cases reinforce the need for emergency physicians to be alert to the possibility of significant head and cervical spine injuries in accidents of apparently moderate impact, particularly if the patient is unconscious.

RECOMMENDATIONS AND FUTURE DEVELOPMENTS Most airbag related adult deaths are preventable if the occupants use seat belts, and keep at least a 10 inch distance between the airbag cover and the front of the chest. The vast majority of drivers (including those of shorter stature) should be able to maintain this distance, and the NHTSA in the US now asks drivers to measure the distance from the sternum to the middle of steering wheel. If this distance is less than 10 inches then the driver can apply to have the bag disconnected or an on/off switch installed. The 10 inch distance is 3 inches for initial activation, 5 inches of seat belt "give", and an extra 2 inches.

Airbag technology continues to evolve. Future advances include the development of "smart" airbags that will adjust to seat position and passenger weight and height. Dual stage inflation systems (that is an initial reduced charge of propellant fires the airbag only to be augmented milliseconds later if a more severe deceleration is detected), side airbags, and driver feet protection airbags are all being developed.

\section{Conclusions}

The reduction in morbidity and mortality since airbags became widely available in new vehicles is well established. This report, the first fatal injury attributed to airbags reported in the UK, highlights the need to be aware of potential hazards associated with their use. Vehicle occupants should always wear seat belts and place children in approved child restraints in the rear of the vehicle. Drivers and passengers, who are unable to maintain the recommended 10 inches from the airbag cover, should consult with vehicle manufacturers over potential solutions including disabling of the airbag mechanism.

We thank Julian Hill of Birmingham Accident Research Centre for his comments on the paper and Dave Foulkes from the Merseyside Police Accident Investigation Unit for crash details.
Contributors

$\mathrm{KC}$ is the principal author and researched and wrote the paper. $\mathrm{PN}$ advised on and helped write the paper. TB treated the patient, gathered some of the initial background information, and advised on the paper. EG provided the postmortem details and commen

$\mathrm{KC}$ is the guarantor for the paper.

Conflict of interest: none.

Funding: none.

1 National Highway Traffic Safety Administration (NHTSA). Special crash investigation program summary tables (http:// Special crash investigation program summary tables

www.nhtsa.dot.gov/people/ncsa/pdf/Summary.pdf). with airbags. F Trauma 1995;38:469-75.

3 Smock WS, Nichols GRD. Airbag induced fatal injuries: a case report. Proceedings of the 45th annual meeting of the American Academy of Forensic Sciences. Boston, MA, February 1993.

4 Jumbelic MI. Fatal injuries in a minor traffic collision. 7 Forensic Sci 1995;40:492-4.

5 Advanced Life Support Group. Advanced cardiac life support, the practical approach. 2nd Ed. London: BMJ Publishing Group, 1998.

6 Larkin GL. Airbag-mediated corneal injury. Am 7 Emerg Med 1991;9:444-6.

7 Daniels RJ, Fulcher RA. An unusual cause of rib fracture following a road traffic accident. F Accid Emerg Med 1997; 14:113-4.

8 Smally AJ, Binzer A, Dolin S, et al. Alkaline keratitis: eye injury from airbags. Ann Emerg Med 1992;21:1400-2.

9 Gross KB, Goets MH, D'Arcy JB, et al. Mechanism of induction of asthmatic attacks initiated by the inhalation of particles generated by the airbag system deployment. $\mathcal{f}$ particles generated by the
Trauma $1995 ; 38: 521-7$.

10 Smock WS, Nichols GR. Airbag module cover injuries. $f$ Trauma 1995;38:489-93.

11 Lau IV, Horsch JD, Viano DC, et al. Mechanism of injury from air bag deployment loads. Accid Anal Prev 1993;25: $29-45$.

12 Brown DK, Roe EJ, Henry TE. A fatality associated with the deployment of an automobile airbag. F Trauma 1995;39: 1204-6.

13 Maxeiner H, Hahn M. Airbag-induced lethal cervical trauma. F Trauma 1997;42:1148-51.

14 Antosia RE, Partridge RA, Virk AS. Air bag safety. Ann Emerg Med 1995;25:794-8.

15 Cacciatori M, Bell RW, Habib NE. Blow-out fracture of the orbit associated with inflation of an airbag: a case report. $\mathrm{Br}$ 7 Oral Maxillofac Surg 1997;35:241-2.

16 Duma SM, Kress TA, Porta DJ, et al. Airbag-induced eye injuries: a report of 25 cases. F Trauma 1996;41: eye injurie $114-9$.

17 O'Halloran HS, Draud K, Stevens JL. Primary enucleation as a consequence of airbag injury. $\mathcal{F}$ Trauma 1998;44:1090. 18 Gault JA, Vichnin MC, Jaeger EA, et al. Ocular injuries associated with eyeglass wear and airbag inflation. F Trauma 1995;38:494-7.

9 Hallock GG. Mechanisms of burn injury secondary to airbag deployment. Ann Plast Surg 1997;39:111-3.

20 Baruchin AM, Jakim I, Rosenberg L, et al. On burn injuries related to airbag deployment. Burns 1999;25:49-52.

21 Vitello W, Kim M, Johnson RM, et al. Full-thickness burn to the hand from an automobile airbag. F Burn Care Rehabil 1999;20:212-5.

22 Buckley G, Setchfield N, Frampton R. Two cases of possible noise trauma after inflation of airbags in low speed car noise trauma after inflation of
crashes. BMf 1999;318:499-500.

23 Saunders JE, Slattery WH, Luxford WM. Automobile airbag impulse noise: otologic symptoms in six patients. airbag impulse noise: otologic symptoms in

24 Huelke DF, Moore JL, Compton TW, et al. Upper extremty injuries related to airbag deployments. I Trauma 1995;38:482-8.

25 Freedman EL, Safran MR, Meals RA. Automotive airbagrelated upper extremity injuries: a report of three cases. $\mathcal{F}$ Trauma 1995;38:577-81

26 Marco F, Garcia-Lopez A, Leon C, et al. Bilateral Smith fracture of the radius caused by airbag deployment. $f$ Trauma 1996;40:663-4.

27 Lancaster GI, DeFrance JH, Borruso JJ. Airbag associated rupture of the right atrium [letter]. $N$ Engl $f$ Med 1993;328:358

28 DeGuzman BJ, Morgan AS, Pharr WF. Aortic transection following airbag deployment. [letter]. $N$ Engl $f$ Med 1997;337:573-4.

29 Hollands CM, Winston FK, Stafford PW, et al. Lethal airbag injury in an infant. Pediatr Emerg Care 1996;12:2012 .

30 Huff GF, Bagwell SP, Bachman D. Airbag injuries in infants and children: a case report and a review of the literature. and children: a case report and a review
Pediatrics 1998;102: 2 (electronic article).

31 Walter DP, James MR. An unusual mechanism of airbag injury. Injury 1996;27:523-4.

32 Hansen TP, Nielsen AL, Thomsen TK, et al. Avulsion of the occipital bone-an airbag-specific injury. Lancet 1999;353: 1409-10. 


\title{
Anaphylaxis and monoamine oxidase inhibitors - the use of adrenaline
}

\author{
M J Fenwick, C L Muwanga
}

\begin{abstract}
A 67 year old woman taking a monoamine oxidase inhibitor (MAOI) presented to the accident and emergency department with an anaphylactic reaction to flucloxacillin. This case highlights the uncertainty regarding the use of adrenaline (epinephrine) in the context of concurrent MAOI use. A summary of the evidence is presented to clarify this.
\end{abstract}

(f Accid Emerg Med 2000;17:143-144)

Keywords: adrenaline; monoamine inhibitors; anaphylaxis

\section{Case report}

A 67 year old woman presented to the accident and emergency (A\&E) department with a history of collapse. She had taken two doses of flucloxacillin for a wound infection prescribed by her general practitioner who was unaware of her previous penicillin allergy. She was also taking phenelzine $15 \mathrm{mg}$ for depression. On initial examination she was flushed and agitated. She had a tachycardia of 120 beats $/ \mathrm{min}$, a blood pressure of $200 / 120 \mathrm{~mm} \mathrm{Hg}$, a respiratory rate of 20 breaths/min, and an oxygen saturation of $98 \%$ on air. She had a swollen tongue with no stridor. An anaphylactic reaction was diagnosed. The safety and use of adrenaline (epinephrine) was debated in view of the potential drug interaction between monoamine oxidase inhibitors (MAOIs) and sympathomimetic drugs. She was treated with oxygen and intravenous (IV) hydrocortisone $200 \mathrm{mg}$, IV chlorpheniramine $10 \mathrm{mg}$, and IV ranitidine $50 \mathrm{mg}$. After 30 minutes she deteriorated, developing stridor that required intuba-

Accepted 14 September 1999

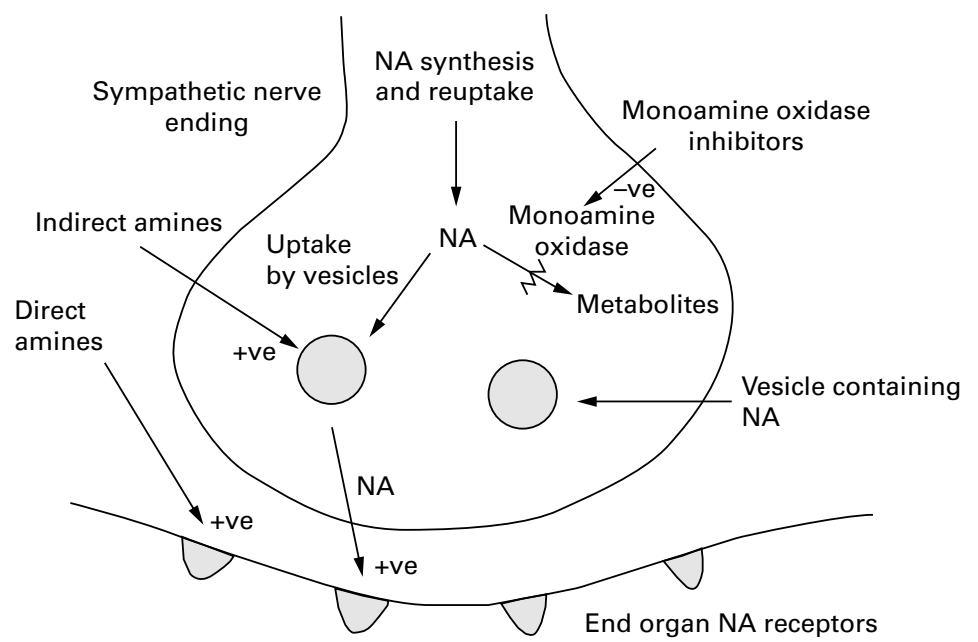

Figure 1 Action of direct and indirect amines at sympathetic nerve endings (NA $=$ noradrenaline). tion. During preparation for intubation and before any induction agents were used her blood pressure dropped to $80 / 20$ and her stridor worsened. It was decided to give her adrenaline and after two boluses of $0.1 \mathrm{mg} \mathrm{IV}$, she rapidly improved. Intubation was achieved easily after gaseous induction of anaesthesia and she was admitted to the intensive care unit. She was extubated the next day and discharged home four days later with no sequelae.

\section{Discussion}

Adrenaline is the treatment of choice in severe anaphylactic reactions, ${ }^{12}$ however there is controversy over the use of adrenaline in patients taking MAOIs. Phenelzine is a non-selective irreversible $\mathrm{MAOI}^{3}{ }^{4}$ and is known to have dangerous interactions with certain foodstuffs and drugs. These include hypertensive crises with sympathomimetic drugs and central excitatory syndromes with tyramine containing foods..$^{5-7}$

MAOIs act by increasing the concentration of noradrenaline in sympathetic nerve endings (fig 1). Sympathomimetic drugs can be subdivided into indirectly acting amines (for example ephedrine, amphetamines) and directly acting amines (for example adrenaline, noradrenaline). ${ }^{34}$ The indirect amines cause increased stimulation of sympathetic neurones and should theoretically result in increased noradrenaline release in patients on MAOIs. This is confirmed by laboratory evidence of potentiation of the cardiovascular response to ephedrine $^{8}$ and clinical case reports of hypertensive crises. ${ }^{6}$ Direct amines act on end organ receptors and should theoretically have no effect on noradrenaline release. However, laboratory evidence is conflicting. Boakes et al showed no potentiation of the cardiovascular response to adrenaline given in a dose of 0.02 $\mathrm{mg} / \mathrm{min}$ to healthy volunteers treated with therapeutic doses of phenelzine for seven days. ${ }^{9}$ Conversely, other studies have shown a three to sevenfold increase in the cardiovascular response to direct amines (using tranylcypromine rather than phenelzine). ${ }^{10}{ }^{11}$ There is a lack of clinical evidence supporting the presence or absence of potentiation. ${ }^{7}$ The confusion in laboratory evidence is reflected in clinical use. The Oxford Textbook of Clinical Pharmacology and Drug Therapy states that adrenaline can cause hypertensive reactions with MAOIs. ${ }^{4}$ A recent update on drug interactions with MAOIs by Livingston and Livingston stated that interactions occur with indirectly acting amines but included adrenaline with these, ${ }^{5}$ while the British National Formulary lists only indirect amines as 
contraindications with MAOIs. ${ }^{12}$ Stockley reviews the evidence and concludes that adrenaline should be used with caution with MAOIs. ${ }^{13}$

\section{Conclusion}

There is confusion by clinicians as to the safety of adrenaline with MAOIs. It is likely that like us, clinicians are often unaware that it is indirectly acting amines that are usually implicated in hypertensive crises with MAOIs. However, the evidence for the safety of adrenaline in the doses used frequently in clinical situations is lacking. We recommend caution with the use of adrenaline in patients taking MAOIs, but that its use in life threatening situations is not contraindicated.

Contributors

M J Fenwick initiated and wrote the paper and performed the literature search. C L Muwanga discussed the idea and edited

the paper.
M J Fenwick is the guarantor of this paper.

Conflict of interest: none.

Funding: none.
1 Brown AFT. Therapeutic controversies in the management of acute anaphylaxis. F Accid Emerg Med 1998;15:89-95.

Fisher M. Treatment of acute anaphylaxis. BMF 1995;311: $731-3$.

3 Hardman JG, Limbird LE, eds. Goodman and Gillman's the pharmacological basis of therapeutics. 9th Ed. New York: McGraw-Hill, 1996: 442-6.

4 Graham-Smith DG, Aronson JK. Oxford textbook of clinical pharmacology and drug therapy. 2nd Ed. Oxford: Oxford University Press, 1992:639.

5 Livingston MG, Livingston HM. Monoamine oxidase nhibitors-an update on drug interactions. Drug Saf 1996;14:219-27.

6 Dawson JK, Earnshaw SM, Graham CS. Dangerous monoamine oxidase inhibitor interactions are still occurring in the 1990s. F Accid Emerg Med 1995;12:49-51.

7 Blackwell B. Monoamine oxidase inhibitor interactions with other drugs. F Clin Psychopharmacol 1991;11:55-9.

8 Elis J, Laurence DR, Mattie H, et al. Modification by monoamine oxidase inhibitors of the effect of some
monotion by monoamine oxidase inhibitors of the effect of some
sympathomimetics on blood pressure. BMF 1967;ii:75-8.

9 Boakes AJ, Laurence DR, Teoh PC, et al. Interactions Boakes AJ, Laurence DR, Teoh PC, et al. Interactions
between sympathetic amines and antidepressant agents in between sympathetic amines
man. $B M \mathscr{\jmath} 1973 ; \mathbf{i}: 311-5$.

10 Cuthbert MF, Vere DW. Potentiation of the cardiovascular effects of some catecholamines by a monoamine oxidase inhibitor. Br $\mathcal{F}$ Pharmacol 1971;43:471-2.

11 Horwitz D, Goldberg LI, Sjoerdsma A. Increased blood pressure responses to dopamine and norepinephrine produced by a monoamine oxidase inhibitor. $\mathcal{F}$ Lab Clin Med 1960;56:747.

12 British Medical Association and the Royal Pharmaceutical Society of Great Britain. British national formulary. London: British Medical Association and the Royal Pharmaceutical Society of Great Britain, 1998;34:568.

13 Stockley IH. Drug interactions. 4th Ed. London: Pharmaceutical Press, 1996: 668-9.

\section{Prolonged coma due to cerebral fat embolism: report of two cases}

Leonidas Gregorakos, Katerina Sakayianni, Despina Hroni, Victoria Harizopoulou, Nikos Markou, Fani Georgiadou, Maria Adamidou

\begin{abstract}
Fat embolism syndrome remains a rare, but potentially life threatening complication of long bone fractures. The true incidence is difficult to assess as many cases remain undiagnosed. Cerebral involvement varies from confusion to encephalopathy with coma and seizures. Clinical symptoms and computed tomography are not always diagnostic, while magnetic resonance imaging is more sensitive in the detection of a suspected brain embolism. Two cases of post-traumatic cerebral fat embolism, manifested by prolonged coma and diffuse cerebral oedema, are presented. The clinical course of the disease as well as the intensive care unit management are discussed.

(F Accid Emerg Med 2000;17:144-146)
\end{abstract}

Keywords: cerebral fat embolism; fat embolism syndrome; coma

Fat embolism syndrome (FES) remains a rare, but potentially life threatening complication of long bone fractures, characterised by pulmonary insufficiency, neurological dysfunction, fever and petechial rash, usually occurring during the first 48 hours after injury. ${ }^{1}$ The true incidence of this syndrome cannot be accu- rately assessed as many subclinical forms remain unrecognised. It varies from $0.5 \%$ to $30 \%$ of fractured patients ${ }^{2}$ with higher rates in multiply injured patients and presents a mean mortality rate of $10 \% .^{3}$ Cerebral involvement has been frequently reported and seems to aggravate the prognosis of FES. ${ }^{4}$ Clinical manifestations vary widely, from a simple alteration of vigilance $(70 \%-85 \%$ of the cases), to seizures and coma. ${ }^{2}$ We present two cases of post-traumatic cerebral fat embolism, manifested by prolonged coma and diffuse cerebral oedema.

\section{Case reports}

CASE 1

An 18 year old man who sustained an open fracture of the left tibia but no head injury, after a motorbike accident, was admitted to the emergency room of our hospital. Upon admission the patient was alert, oriented, normotensive, and eupnoeic. Neurological examination showed no abnormalities. Two hours later, external fixation of his fracture was performed under general anaesthesia. After complete recovery from anaesthesia he was transferred to the orthopaedic department; he was haemodynamically stable and had a normal respiratory pattern. Twelve hours postoperatively he developed signs of FES including fever $\left(>39^{\circ} \mathrm{C}\right)$, tachycardia, 
petechiae over the shoulder area, hypoxaemia, oliguria, and thrombocytopenia. Six hours later he was unconscious, responding only to painful stimuli. Neurological examination demonstrated a Glasgow coma score of 5 (eye opening 1 , motor response 3 , verbal response 1 ), and a normal reaction of both pupils to light. An immediate endotracheal intubation was performed because of unconsciousness and respiratory insufficiency. The patient was transferred to the intensive care unit (ICU) and mechanical ventilation initiated. Chest radiography on ICU admission demonstrated diffuse pulmonary infiltrates. Cerebral computed tomography, performed shortly after mental status deterioration, revealed diffuse brain oedema. Antioedema treatment was instituted, and mild hypocapnia was induced. Retinal examination performed on day 2 demonstrated characteristic cottonwool spots across the vascular beds, which are indicative of fat embolism. Magnetic resonance imaging (MRI), performed on day 3 showed multiple areas of increased intensity in the cerebral white matter, which confirmed the diagnosis of cerebral fat embolism. The patient remained under mechanical ventilation, general supportive care in the ICU, and regular neurosurgical evaluation. High doses of methylprednisolone $(30 \mathrm{mg} / \mathrm{kg} / 8$ hours intravenously) were administered for three doses, followed by prednisolone $50 \mathrm{mg} /$ day, intravenously, tapering off after one week. A tracheostomy was performed and mechanical ventilation continued for 22 days. Thereafter, he was breathing spontaneously through the tracheostomy. One month after initial admission he started opening his eyes to intense stimuli, and computed tomography showed resolution of cerebral oedema. The tracheostomy tube was removed on the 35th day of hospitalisation, by which time he had a progressive resumption of consciousness and improving responsiveness to external stimuli. He was in the ICU for six weeks, and his entire hospital stay after the accident was two months. He was discharged from the hospital without any neurological sequelae. MRI performed before discharge detected no abnormalities.

CASE 2

A 20 year old man sustained bilateral closed tibia fractures and abdominal trauma after a traffic accident. Upon his admission to the emergency room no signs of craniocerebral injury were present. Neurosurgical examination detected no neurological abnormalities, with a Glasgow coma score of 15 . Blood pressure was $140 / 90 \mathrm{~mm} \mathrm{Hg}$ and heart rate 120 beats $/ \mathrm{min}$. As indicated by intraperitoneal lavage, an urgent laparotomy was performed, which showed rupture of the mesenterium. Limited small intestine resection and enteroentero anastomosis were performed. At the same time the patient underwent closed reduction and cast immobilisation of his fractures. After surgical intervention and complete recovery from anaesthesia, the patient was transferred extubated to the ICU. Six hours after admission the patient had a fever $\left(39^{\circ} \mathrm{C}\right)$, became cyanotic, comatose, and had seizures. His Glasgow coma score was 4 (eye opening 1, motor response 2, verbal response 1), while pupils were equal in size and reactive to light. He was immediately intubated and mechanically ventilated. In addition, signs of systemic fat embolism, such as tachycardia, conjunctival petechiae, hypoxaemia, and diffuse pulmonary infiltrates on chest radiography, were present. Laboratory analysis revealed thrombocytopenia and anaemia. Arterial blood gas analysis showed a partial oxygen tension of $7.73 \mathrm{kPa}$ (58 $\mathrm{mm} \mathrm{Hg}$ ) and partial carbon dioxide tension of $4.27 \mathrm{kPa}(32 \mathrm{~mm} \mathrm{Hg})$.

On day 2, computed tomography of the brain showed diffuse cerebral oedema, without any change in neurological status. He remained under mechanical ventilation for 15 days, receiving the same treatment as case 1 . MRI was performed on day 5 , which showed diffuse high intensity lesions in the subcortical and periventricular white matter. During his stay at the ICU he suffered two episodes of nosocomial pneumonia. Serial blood culture and protected brush specimen cultures were obtained. Pseudomonas aeruginosa was isolated from bronchoalveolar lavage fluid and an appropriate antibiotic treatment was given, according to sensitivity. He was extubated on day 15 and was transferred to the neurosurgical department five days later with moderate disorientation. MRI of the brain on day 25 demonstrated a substantial resolution of the previous hyperintense lesions. He was finally discharged from the hospital 35 days after the accident without any neurological deficit.

\section{Discussion}

FES with fat droplets larger than $8 \mu \mathrm{m}$ in diameter occurs in more than the $90 \%$ of patients with long bone fractures. This syndrome denotes clinical or subclinical respiratory insufficiency, and usually runs a mild course and responds well to measures for ventilatory support. ${ }^{1}$ In our patients the diagnosis was established by Gurd's criteria, ${ }^{5}$ the characteristic fat globules on retinal examination, and the findings on brain computed tomography and MRI. There are two theories explaining the pathogenesis of FES. According to the "mechanical" theory, free fat particles from the bone marrow enter torn vein sinusoids at the site of the fracture and embolise the pulmonary arterioles. The "chemical" theory suggests that fat emboli arise from plasma fat when, through some type of systemic stimulus associated with trauma and other medical conditions, chylomicrons coalesce and fuse to form larger fat globules. ${ }^{5}$ Victims of the fulminant form of the syndrome on postmortem examination present occlusion of small blood vessels by fat emboli with areas of brain microinfarction and haemorrhage.${ }^{6}$ Due to cerebral fat emboli, the brain often appears oedematous and shows an inflammatory reaction while the numerous petechiae can cover the surface of the brain. ${ }^{8}$ Endothelial damage results from toxic free fat and capillary obstruction by fat globules 
with associated platelet aggregation, release of vasoactive substances, and development of coagulopathy. ${ }^{9}$

The presence or the reopening of a patent foramen ovale and a right to left shunt due to pulmonary hypertension is associated with an increased risk for systemic manifestations of FES. ${ }^{10}$ However, several studies have failed to demonstrate any intracardiac shunts in patients suffering from this syndrome. ${ }^{811}$ Published studies remain undecided whether a patent foramen ovale or other intracardiac defects are prerequisites for the development of cerebral symptoms.

Our patients are characteristic cases of cerebral fat embolism, which was followed by a severe course of disease in the ICU. They responded to conventional treatment and administration of corticosteroids. Among several pharmacological treatments, only steroids have proved to be beneficial in the prophylaxis and treatment of FES, both in high and low doses. ${ }^{12-14}$ The mode of action has not been elucidated, but seems to be related to their anti-inflammatory and antiadhesive effects.

The long stay in the ICU was due to the increased intracranial pressure, following cerebral oedema. These cases suggest that cerebral oedema plays a major part in the neurological deterioration in the fulminant type of FES and that cerebral computed tomography is indicated in such patients. ${ }^{15}$ Computed tomography is also useful in excluding traumatic cerebral involvement in multiple trauma patients presenting with deterioration in their mental state, but is not specific for the diagnosis of cerebral fat embolism. ${ }^{16} \mathrm{MRI}$ is a better diagnostic tool for the confirmation of brain embolism, as it is more sensitive in the detection of degenerative and vascular injuries and non-haemorrhagic contusion. In addition, it seems to correlate well with the clinical neurological course. ${ }^{17} 18$

The patients described above, despite the initial severe neurological syndrome and prolonged coma, had complete cerebral recovery. Several studies report that cerebral dysfunction associated with FES appears to be reversible in the majority of the cases, so physicians should not give up hope even in the most severe forms of the syndrome. ${ }^{8101119}$ It is likely that fat emboli of very small diameter cause reversible ischaemia and transient perivascular oedema, allowing recovery from cerebral dysfunction. ${ }^{17}$

Cerebral fat embolism should always be suspected when severe neurological dysfunction appears in a patient with long bone fractures, in the absence of an initial major head injury. Although the diagnosis may be straightforward in patients with isolated long bone fractures, it may be difficult in the multiple trauma patient with head injury or under sedation. In addition, hypoxia may be associated with pulmonary contusion and infection and petechiae may occur after blood transfusion.
Many authors have suggested that early open reduction and surgical stabilisation of long bone fractures may reduce the incidence of FES. $^{2}{ }^{10}$ Repeated manipulation of the fractured fragments may further stimulate the release of bone marrow fat into the circulation. ${ }^{10}$ Similarly, the type of surgical fixation seems to influence the incidence of fat embolisation. External fixation and plate osteosynthesis have several advantages compared with intramedullary nailing techniques, which further increase intramedullary pressure and promote fat emboli release.$^{10}{ }^{20}$ However, the syndrome is frequently observed despite prompt surgical intervention.

As pathophysiology of the syndrome still remains obscure, attention should be paid to prevention and early recognition of this entity. Optimal immobilisation, adequate fluid and blood replacement, meticulous monitoring, and use of steroids are principles commonly accepted in current treatment. ${ }^{2}{ }^{10}$

Contributors

All of the authors listed above have contributed substantially to the collection of data and writing of the paper.

Leonidas Gregorakos is the guarantor for the paper.

Conflict of interest: none.

Funding: none.

1 Fulde GW, Harisson P. Fat embolism: a review. Arch Emerg Med 1991;8:233-9.

2 Estèbe JP. Des emboles de graisse au syndrome d'embolie graisseuse. Ann Fr Anesth Reanim 1997;16:138-51.

3 Fabian TC, Hoots AV, Stanford DS, et al. Fat embolism syndrome: prospective evaluation in 92 fracture patients. Crit Care Med 1990;18:42-6.

4 Jacobson TM, Terrence CF, Reinmuth OM. The neurologic manifestation of fat embolism. Neurology 1986;36:847-51.

5 Gurd AR. Fat embolism: an aid to diagnosis. 7 Bone foint Surg Br 1970;52:732-7.

6 Findlay M, DeMajo W. Cerebral fat embolism. Can Med Assoc F 1984;131:755-7.

7 Meeke RI, Fitzpatrick GJ, Phelan DM. Cerebral oedema and fat embolism syndrome. Intensive Care Med 1987;13: and fat 2 .

8 Needham AP, McLean AS, Stewart DE. Severe cerebral fat embolism. Anaesth Intensive Care 1996;24:502-4.

9 Erdem E, Namer IJ, Saribas O, et al. Cerebral fat embolism studied with MRI and SPECT. Neuroradiology 1993;35: 199-201.

10 Ten Duis HJ. The fat embolism syndrome. Injury 1997;28: $77-85$.

11 Ibanez CN, Collado NR, Gavina SI, et al. Fat embolism syndrome without respiratory failure. Clinical Intensive Care 1999;10:101-3.

12 Kallenbach J, Lewis $M$, Zaltzman $M$, et al. Low-dose corticosteroid prophylaxis against fat embolism. F Trauma 1987;27:1173-6.

13 Gregorakos L, Dimopoulos G, Mavropanou D, et al. Fat embolism syndrome in traumatized patients: a five year experience of a single intensive care unit. Applied Cardiopulmonary Pathophysiology 1996;6:105-9.

14 Schonfeld SA, Ploysonsang Y, Dilisio R, et al. Fat embolism prophylaxis with corticosteroids: a prospective study in high risk patients. Ann Intern Med 1983;99:438-43.

15 Sakamoto T, Sawada Y, Yukioka T, et al. Computed tomography for diagnosis and assessment of cerebral fat embolism. Neuroradiology 1983;24:283-5.

16 Citerio G, Bianchini E, Beretta L. Magnetic resonance imaging of cerebral fat embolism: a case report. Intensive Care Med 1995;21:679-81.

17 Satoh H, Kurisu K, Ohtani M, et al. Cerebral fat embolism studied by magnetic resonance imaging, transcranial Doppler sonography, and single photon emission computed tomography: case report. F Trauma 1997;43:345-8.

18 Vincetti-Rouquette I, David H, Borne M, et al. Intérêt de l'IRM dans l'embolie graisseuse cérébrale. Ann Fr Anesth Reanim 1998;17:278-80.

19 Scopa M, Magatti M, Rossitto P. Neurologic symptoms in fat embolism syndrome. F Trauma 1994;36:906-8.

20 Christie J, Robinson CM, Pell AC, et al. Transcardiac echocardiography during invasive intramedullary procedures. $\mathcal{f}$ Bone foint Surg Br 1995;77:450-5. 


\title{
Air rifle injury to the oropharynx. The essential role of computed tomography in deciding on surgical exploration
}

\author{
T Hung, P Huchzermeyer, A E Hinton
}

\begin{abstract}
Gunshot wounds specific to the oropharynx are extremely rare with no reported cases of such injury in the world literature. The importance of such cases rests on the use of modern imaging techniques including computed tomography, magnetic resonance imaging, and vascular imaging in the making of management decisions and particularly in deciding the need for exploration of such an injury. In our case a conservative approach was adopted in view of the computed tomography finding and the stable clinical condition of the patient.

(F Accid Emerg Med 2000;17:147-148)
\end{abstract}

Keywords: oropharynx; gunshot wound

Gunshot injuries and fatalities are common in the United States where the firearm regulations are more lenient than those of the UK. However there has been a surge of gunshot incidents in the UK in recent years when increasing violence in the media and the deinstitutionalisation of mental patients were contributory factors. Air rifles may be possessed without a certificate in the UK if they are not of type declared dangerous by the Firearms Rules 1969. An air rifle should discharge a pellet with a kinetic energy below $16.3 \mathrm{~J}(12 \mathrm{ft} \mathrm{lb})$. Above these levels the weapon is classified as a firearm under section 1 of the Firearm Act 1968. Air rifle injuries can range from trivial to fatal depending on the site of injury and the vascular damage. The majority of entry wounds reported in the literature are external. We report the first case in which our patient has an intraoral entry wound. The use of emergency computed tomography was essential in the localisation of the pellet and the formulation of a management plan.

Department of

Otolaryngology, St George's Hospital,

London

T Hung

P Huchzermeyer

A E Hinton

Correspondence to: Mr Terry Hung, Senior House Officer, $16 \mathrm{St}$ Clements Mansions, Lillie Road, Fulham, London SW6 $7 \mathrm{PG}$

(e-mail: 113302.3310@ compuserve.com)

Accepted 14 September 1999

\section{Case report}

A 22 year old man claimed to have accidentally triggered his air rifle, which was aiming at his open mouth. He sustained a gunshot wound to his oropharynx. There was a minimal amount of bleeding from his oral cavity. He did not complain of any breathing difficulty. $\mathrm{He}$ complained only of discomfort of the left side of his throat and neck.

He looked remarkably calm on arrival at the accident and emergency department. There was no stertor or stridor. His cardiovascular status was stable. His oxygen saturation was $99 \%$ on air throughout the admission. There was minimal swelling and tenderness of the left

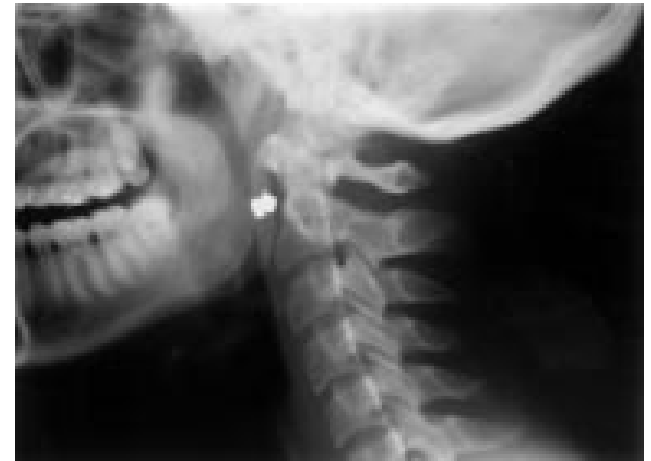

Figure 1 Lateral soft tissue neck radiograph showing the pellet anterior to the odontoid peg.

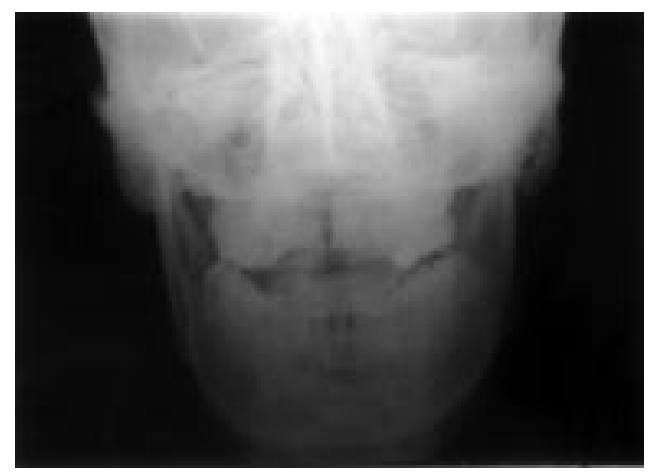

Figure 2 Posteroanterior neck radiograph showing the pellet in the anterolateral soft tissue of the neck.

upper anterior triangle of his neck. Surgical emphysema was not elicited. A $1 \mathrm{~cm}$ entry wound was noted at the middle portion of the anterior faucial pillar. Flexible pharyngoscopy revealed a bloodstained tongue base but no active haemorrhage. The airway was completely patent.

The soft tissue neck radiograph showed a radio-opaque pellet just anterior to the base of the odontoid peg (figs 1 and 2). The emergency computed tomogram of the neck showed the metallic pellet lying in the prevertebral soft tissues anterior to the transverse process of the second cervical vertebra (fig 3 ). The pellet was found to lie within $1 \mathrm{~cm}$ of and medial to the left internal carotid artery.

The patient was treated with intravenous cefotaxime and metronidazole prophylactically. Oral intake was started after 24 hours of close observation. He was discharged on the third day in view of satisfactory aerodigestive function. The decision was made against retrieval of the pellet by surgical exploration as the procedure could be more hazardous than the risks of leaving the pellet undisturbed The patient was reviewed after two months without 


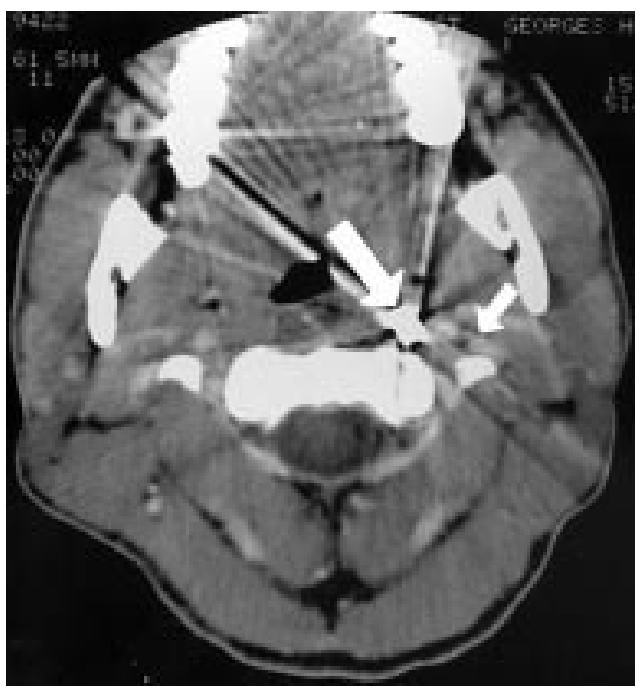

Figure 3 Contrast enhanced computed tomogram showing the metallic pellet (large arrow) lying to the left of the midline in the prevertebral soft tissue anterior to the transverse process of the axis (small arrow shows left internal carotid artery).

any sequelae. As the pellet was thought to be an iron alloy, he was warned against entering any strong electromagnetic field including magnetic resonance scanning. $\mathrm{He}$ will be treated expectantly if complications arise.

\section{Discussion}

It is estimated that one person each year dies from an air powered weapon injury in the UK. ${ }^{1}$ Fatalities and injuries are most commonly accidents, but deliberately inflicted injuries do occur. Airguns are dangerous weapons when inappropriately handled and should not be considered as toys. Basic ballistics verifies that a projectile's potential to disrupt tissue is determined by both its mass and its velocity. Modern day pneumatic rifles allow the generation of muzzle velocities of up to 350 feet per second. Speeds of 150 feet per second and 200 feet per second are required for skin penetration and bone penetration, respectively. ${ }^{2} \mathrm{~A}$ pressure wave follows the projectile with the creation of a "temporary cavity" which could have a significant wounding mechanism. Inelastic tissues such as liver are far more susceptible to disruption by the temporary cavity than are more flexible body tissue such as muscle, bowel wall, and lung. ${ }^{3}$ Nichols and Sens used cytological technique to analyse direct ballistic trauma in several tissue type, most notably in muscular tissue. ${ }^{4}$ Progressive damage to skeletal and cardiac muscle was seen in multiple preparations. This ranged from partial separation of the fascicles to cytoplasmic homogenisation and nuclear rupture.

Most of the world literature described external gunshot wounds of the head, chest, abdomen, and the extremities. Only two bizarre and fatal cases of gunshot injuries involving the human orifices were reported, namely intrarectal and intranasal routes. ${ }^{56}$ Both patients described had past psychiatric history. Our patient is the first case recorded with gunshot injury via an intraoral route and he denied such a past psychiatric history.

The first priority in the management of gunshot injury to the head and neck region should always be the securing of the airway, breathing, and circulation. There is little disagreement in the literature about how to treat penetrating projectile wounds of the chest and abdomen or those that disrupt major blood vessels or bone. Ironically, most of the dispute concerns treatment of the least lethal injuries and how to manage the soft tissue disruption.

Pathology of the oropharynx, unlike their external counterpart is notoriously difficult to visualise in the emergency situation. Systemic signs are only a rough guide to the progression of complications. Acute radiological evaluation of gunshot wounds has been established in other organs. ${ }^{7}$ Imaging is most important in the definitive management of gunshot injuries to the head and neck. The soft tissue neck radiograph is only a rough guide to the anatomical position of the pellet. It reveals insufficient details of the soft tissue anatomy. Computed tomography allows much more accurate localisation of the pellet in respect to the important anatomical structures. In fact Milroy et al had successfully located both the pellet and the fragments using computed tomography. ${ }^{1}$ Contrast enhancement allows relatively precise localisation of the pellet in respect of the main blood vessels, the left internal carotid artery in our case. The use of emergency computed tomography was essential as it gave us reassurance of the integrity of the vasculature and it allowed us to adopt a conservative management approach in this emergency senario.

The decision of non-retrieval of the pellet on a definitive basis was an exercise of risk management. Surgical access of the oropharynx will require the commando approach when mandibulectomy is performed. ${ }^{8}$ This procedure has a very high morbidity.

Conflict of interest: none.

Funding: none.

1 Milroy CM, Clark JC, Carter N, et al. Air weapon fatalities. f Clin Pathol 1998;51:525-9.

2 Ford EG, Senac MO, McGrath N. It may be more significant than you think: BB air rifle injury to a child's head. Pediatr Emerg Care 1990;6:278-9.

3 Fackler ML. Gunshot wound review. Ann Emerg Med 1996; 28:194-203.

Nichols CA, Sens MA. Cytologic manifestations of ballistic injury. F Clin Pathol 1991;95:660-9.

5 Prahlow JA. Suicide by intrarectal gunshot wound. Am 7 Forensic Med Pathol 1998;19:356-61.

6 Lee KA, Opeskin K. Gunshot suicide with nasal entry. Forensic Sci Int 1995;71:25-31.

7 Phiilips CD. Emergent radiologic evaluation of the gunshot wound victim. Radiol Clin North Am 1992;30:307-24.

8 DeSanto LW, Whicker JH, Devine KD. Mandibular osteotomy and lingual flaps: use in patient with cancer of the tonsil area and tongue base. Archives of Otolaryngoloy 1975;101:652. 


\title{
A useful form of glue ear
}

\author{
J R Benger, P H Davies
}

\begin{abstract}
Children and adults commonly present to the emergency department with a foreign body lodged in the ear. Over the past 15 years techniques for cyanoacrylate ("superglue") assisted foreign body removal have been described, but are not widely employed. Two cases of successful and one of unsuccessful removal using this technique are reported, and some advice is offered to aid others.

(f Accid Emerg Med 2000;17:149-150)
\end{abstract}

Emergency

Department, Frenchay

Hospital, Beckspool

Road, Frenchay,

Bristol BS16 1LE

J R Benger

P H Davies

Correspondence to: Dr Benger, Specialist Registrar In Emergency Medicine (e-mail:

JB2@cableinet.co.uk)

Accepted 23 October 1999

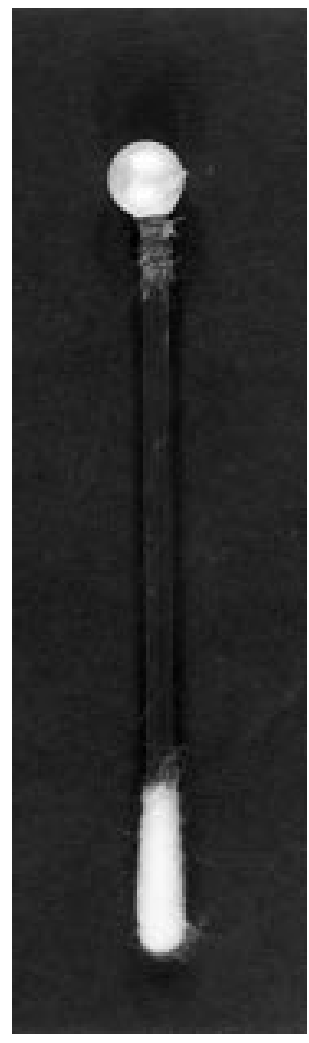

Figure 1 Foreign body (plastic pearl) removed in case 2 using cyanoacrylate glue. The pearl is still adherent to the hollow plastic tube used in the extraction.
Keywords: child; cyanoacrylate; ear; foreign body

Foreign body within the ear is a common problem presenting to emergency departments. Most patients are inquisitive children in the 2 to 8 age group, ${ }^{1}$ but adults can also present in this way. ${ }^{2}$ Patients are more commonly male and of low socioeconomic status. ${ }^{3}$ During a recent 12 month period 74 patients (representing approximately one in 500 new attendances) presented to our emergency department with a foreign body lodged in the ear. Of these $30(41 \%)$ were adults and 44 that of one in 1792 new patient registrations reported from the John Hopkins emergency department in $1987 .{ }^{3}$

Many different techniques have been advocated for the removal of foreign bodies lodged in the ear, ${ }^{4}$ though very few of these have been formally assessed in any scientific way, relying more on anecdote and experience. ${ }^{5}$

We report two cases of successful and one of unsuccessful removal of a foreign body from the external auditory canal using cyanoacrylate "superglue", and make some further observations based upon our experiences.

\section{Technique for removal}

In the following cases we used a blunt plastic stick, such as that contained in a "cotton bud". The cotton wool was removed and a small amount of cyanoacrylate glue applied. This was then introduced into the ear under direct vision until the foreign body was contacted. A drying time of 30 to 60 seconds was allowed, after which the foreign body was extracted with a smooth, pulling motion.

\section{Case reports}

CASE 1

A general practitioner referred a 60 year old woman with an asymptomatic foreign body in her ear. Removal was initially attempted with forceps, but the patient found this too painful. Instead the foreign body was removed easily using cyanoacrylate glue. $(59 \%)$ children. This rate is rather more than
CASE 2

A 17 year old woman placed a plastic pearl in her right ear and was unable to remove it. In the emergency department the pearl was easily visualised and removed using cyanoacrylate glue (see fig 1).

\section{CASE 3}

A 4 year old girl pushed a plastic bead into her ear. The bead was visualised deep within the ear canal, but several attempts at removal using cyanoacrylate glue failed due to a lack of patient cooperation and the plastic stick becoming detached from the bead. The patient was referred for removal under general anaesthesia.

\section{Discussion}

The first reported use of glue to remove a foreign body from the ear was published in $1977 .^{6}$ This described two successful cases in which a general purpose adhesive was applied to the end of a flexible plastic rod. Three subsequent reports using cyanoacrylate glue have been published, the earliest in $1984 .^{7}$ In 1989 Pride and Schwab claimed the first reported use of cyanoacrylate glue for the successful removal of a foreign body from the ear, and suggested that a larger series would be helpful. ${ }^{8}$ Four years later Hanson and Stephens successfully applied this technique to the nose and ear of a 3 year old girl and 14 year old boy respectively, ${ }^{9}$ but beyond this no further information or evaluation has been published.

Though it is clear that cyanoacrylate extraction of foreign bodies can be highly successful, the efficacy of this technique in relation to the many others available remains uncertain. It is likely to be most useful in extracting hard, spherical objects such as those described above. These are difficult to remove with forceps, but may be amenable to extraction using a Fogarty biliary catheter ${ }^{10}$ or suction device, ${ }^{11}$ and as a result the role and value of cyanoacrylate techniques remains unclear.

Above all, these cases illustrate the requirement for a cooperative patient, good light, direct vision, and manual dexterity. Although Thompson ${ }^{7}$ and Hanson and Stephens ${ }^{9}$ both report success with children, we are doubtful whether many youngsters are capable of staying still for the time it takes the glue to dry, and would suggest that in the absence of sedation this technique may prove most applicable to adults.

\section{Conclusion}

Removal of foreign bodies from the ear using cyanoacrylate glue is more useful in adults than children as a high degree of cooperation is required. There is considerable scope for further research into this particular removal 
technique, and for a formal comparison of the various extraction methods currently in use.

Contributors

Jonathan Benger and Philip Davies worked together to initiate and develop this case report. Jonathan Benger collected the clinical data and drafted the paper. Philip Davies contributed to the literature review and edited the paper.

Both authors act as guarantors for the paper.

Conflict of interest: none.

Funding: none.

1 Baker MD. Foreign bodies of the ears and nose in childhood. Pediatr Emerg Care 1987;3:67-70.

2 Bressler K, Shelton C. Ear foreign body removal: a review of 98 consecutive cases. Larygoscope 1993;103:367-70.

3 Fritz S, Kelen GD, Siverton KT. Foreign bodies of the external auditory canal. Emerg Med Clin North Am 1987;5: 183-91.
4 Stool SE, McConnel CS. Foreign bodies in pediatric otolaryngology. Clin Pediatr (Phila) 1973;12:113-6.

5 Morris MS. New device for foreign body removal. Laryngoscope 1984;94:980

6 Zeinulabdeen $M$. New touch and pull method to remove foreign bodies from the ear. F Indian Med Assoc 1977;68: $97-8$.

7 Thompson MP. Removing objects from the external auditory canal. N Engl f Med 1984;311:1635.

8 Pride H, Schwab R. A new technique for removing foreign bodies of the external auditory canal. Pediatr Emerg Care 1989;5:135-6.

9 Hanson RM, Stephens M. Cyanoacrylate assisted foreign body removal from the ear and nose in children. Pediatric Child Health 1994;30:77-8.

10 Virnig RP. Nontraumatic removal of foreign bodies. Minn Med 1972;55:1123.

11 Jensen JH. Technique for removing a spherical foreign body from the nose or ear. Ear Nose Throat f 1976;55:46-7. 